\title{
Questões de metodologia - parte 2
}

\author{
Leilah Santiago Bufrem
}

\begin{abstract}
Resumo
A Profa. Dra. Leilah Santiago Bufrem, especialista em metodologia e produção cientifica, responde questões dos alunos do Curso de Pós-Graduação em Ciência, Gestão e Tecnologia da Informação (PPCGI/UFPR) e da Graduação em Gestão da Informação (CGI/UFPR). Nesta segunda parte da entrevista a Profa. Leilah esclarece, com ênfase nas peculiaridades da pesquisa em Ciências Sociais Aplicadas e Ciência e Gestão da Informação, os seguintes aspectos: as condições da coleta e análise de dados, as diferenças entre pesquisa ação e pesquisa participante, as estratégias para identificar fontes seguras e de qualidade para a elaboração do referencial teórico e, as características gerais da produção científica.
\end{abstract}

\section{Palavras-chave}

Metodologia da pesquisa; Ciências Sociais Aplicadas; Ciência da Informação; Pesquisas científicas.

0 desafio acadêmico nos instiga a retomar a entrevista iniciada no primeiro número desta revista, reiterando o agradecimento aos estudantes e aos editores. As perguntas dos primeiros não somente incentivaram as reflexões para este segundo conjunto de perguntas, mas se traduzem em desafios no caminhar constante dos intelectuais que consideram a pesquisa uma arte sempre passivel de aperfeiçoamento. 0 trabalho dos editores, por sua vez, gerou imediata e positiva receptividade ao primeiro número desta revista de extremo cuidado editorial, motivada certamente pelo entusiasmo dos que legitimam suas ações na missão universitária.

A primeira parte da entrevista cuidou de questões voltadas prioritariamente à dimensão que Bruyne, Herman e Schoutheete (1977) denominam de pólo epistemológico da pesquisa, caracterizado por uma espécie de vigilância interna do pesquisador em relação à delimitação do tema e construção do problema, às reflexões introdutórias da pesquisa, aos processos discursivos e aos critérios de delimitação, recorte e representatividade amostral.

Ao retomar o diálogo, cujas respostas não se podem considerar como definitivas, já que o fazer pesquisa é uma prática dialética, sem fórmulas preconcebidas, agradeço mais uma vez a oportunidade de repensar modos, especificidade e caracteristicas de produção científica, dessa feita com ênfase maior nas peculiaridades da pesquisa em Ciências Sociais Aplicadas e, mais especificamente, em Ciência e Gestão da Informação.

Leilah Santiago Bufrem 


\section{Quais as técnicas de coleta e análise de dados mais utilizadas em pesquisas na área de ciências sociais?}

A resposta a essa questão demandaria um percurso investigativo sobre dados empíricos comprobatórios. Na impossibilidade de realizálo, destaco pesquisas sobre a produção na área, cujos resultados demonstram que, de um modo geral, esses estudos são de caráter empírico e funcionalista. Contam, como modo de aproximação com a realidade, com técnicas como questionários, entrevistas e observações.

É o caso, por exemplo, do estudo analítico de Martins sobre as teses e dissertações apresentadas nos programas de pós-graduação de ciências sociais aplicadas das universidades de São Paulo, apresentado ao XX Encontro Anual da Anpad (1996), que revela o predomínio de trabalhos empíricos, positivistas, sistêmicos e funcionalistas, que se utilizam especialmente de técnicas como questionários, entrevistas e observação. Essa constatação é reiterada por Vergara e Peci (2003), na análise de 194 artigos publicados nos anos 2000 e 2001 em revistas estrangeiras e brasileiras. Também chama a atenção das autoras a utilização cada vez maior do uso da triangulação, combinando-se técnicas de pesquisa tais como entrevistas, observações, questionários, utilização de bancos de dados de documentos e fontes alternativas, que ensejam uma visão polifacetada do objeto de estudo.

Os estudos que vêm sendo realizados pelo Grupo de Pesquisa do $\mathrm{CNPq}$, Educação, Pesquisa e Perfil Profissional, na Universidade Federal do Paraná, revelam inicialmente que predominam, na área de Ciência da Informação (CI), as pesquisas de natureza exploratória ou descritiva, com a utilização principalmente de questionários e entrevistas. As constatações desse grupo coincidem com o estudo de Silva (2010), que define um corpus com artigos de pesquisa da revista Ciência da Informação para estudar o delineamento e a análise das tendências das pesquisas na área, no período de 2000 a 2009. A partir de uma análise das pesquisas quanto aos seus objetivos, às estratégias adotadas, aos enfoques, aos tipos de análises e às técnicas utilizadas, constata que elas se caracterizam como exploratórias, e em menor extensão como descritivas e metodológicas, com predomínio de técnicas como o questionário, a entrevista e a observação. Esses resultados sobre a pesquisa em CI parecem, portanto, coincidir com os obtidos na área mais abrangente das ciências sociais aplicadas.

\section{Por que ou quais as dificuldades para a CI desenvolver suas próprias metodologias?}

Importa perguntar inicialmente se existem concretamente essas dificuldades e, em caso positivo, aventar hipóteses que as justifiquem. A literatura indica que a CI vem se constituindo como ciência a partir do século XX, enquanto a metodologia científica, como auxílio à construção de representações adequadas dos objetos construídos cientificamente, tem sua gênese nos séculos XVI e XVII, com a valorização do pensamento racional. A partir do século XVIII, a ciência passa a traduzir o desenvolvimento e a consolidação das estruturas de pensamento emergentes no período anterior, durante a revolução científica, refletindo as transformações políticas e intelectuais de então. Essa constatação histórica já explica, de certo modo, que a CI não pode ser comparada a outras ciências já amadurecidas e respaldadas por metodologias adequadas aos seus objetos.

Desse modo, eu diria, existem desafios a essa ciência, em fase de institucionalização, especialmente porque os limites de seu domínio científico são caracterizados pela interpenetração disciplinar. Esse caráter, se por um lado favorece o diálogo e a construção de objetos de pesquisa emergentes, por outro exige para sua delimitação o repensar de campos e domínios que se entrecruzam. São tomados mais frequente $\mathrm{e}$ intensamente na área de CI os conteúdos relativos 
à informática, à administração e à linguística, campos que instrumentalizam e ampliam as possibilidades da área. Assim, a produção intelectual reveste-se de pragmatismo, de modo análogo à área de administração, situada por Machado-da-Silva, Cunha e Amboni (1990) dentro do paradigma funcionalista. Os autores consideram as influências presentes na produção da área de administração como resultantes de obras de "foco gerencialista e qualidade duvidosa", segundo eles "mais próprias de livrarias de aeroportos que de bibliotecas universitárias", em detrimento de uma literatura mais instigante, de inclinação vanguardista. Esse alerta gerou impacto e polêmica entre os pesquisadores, tanto da área de administração quanto daquelas subsidiadas pelos conteúdos "gerencialistas", como a CI.
Com efeito, é de se considerar que, ao tomar de empréstimo autores e obras de outros domínios em prejuízo de suas raízes, a CI sofre o risco não somente de se distanciar de seus problemas e de suas raízes, mas de ampliar as dificuldades para desenvolver suas próprias metodologias, tratando superficialmente seus objetos de estudo. Desse modo, as críticas aos modelos positivistas e funcionalistas dirigem-se também à literatura que toma de empréstimo não somente conceitos, mas métodos e técnicas nem sempre adequados ao seu campo de conhecimento. Embora esses modelos e estratégias sejam tomados pelos pesquisadores da CI, devido ao nível de consolidação ainda incipiente da área, eles podem dificultar a compreensão da realidade e a valorização do que se costuma denominar de pesquisa qualitativa.

3. Quais as metodologias utilizadas pela/na CI na análise de produção cientifica em áreas ou temáticas diferentes, por exemplo, metodologias utilizadas pela/na CI para analisar a produção cientifica sobre a mulher, ou sobre o negro, ou ainda sobre a inclusão digital?

A produção científica em qualquer área do conhecimento pode ser analisada com finalidades, enfoques e metodologias diversos e com uso de técnicas variadas. Como objeto de pesquisa, a produção científica sobre temas definidos como mulher, negro ou outros temas sociais vem sendo estudada por meio de análises de conteúdo de corpora definidos, delimitados por recortes temáticos, espaciais ou temporais e em geral fundamentada em dados empíricos. Têm sido utilizados principalmente enfoques bibliométricos, infométricos ou webométricos para esse tipo de análise ou de avaliação da produção científica, visando-se a reconhecer tendências temáticas e metodológicas, perfil de autoria e dos canais de comunicação utilizados. Como metodologias para a análise de um corpo de conhecimento específico, esses enfoques podem ser enriquecidos por meio da análise contextual, apresentada por Falkingham e Reeves (1996) como processo revelador de significativas relações entre as informações coletadas. Outro enfoque valioso para complementação dos estudos métricos sobre a produção de conhecimento tem sido a análise de domínios específicos de conhecimento, historicamente delineados por meio das relações entre teoria e empiria, conjugados em prol da construção do saber científico.

\section{Qual a diferença entre a pesquisa ação e a pesquisa participante?}

Quando realiza uma pesquisa como participante, o pesquisador faz parte da vida da comunidade, grupo ou ambiente observado e sua participação pode ser mais ou menos atuante, dependendo dos seus laços com o ambiente. Esse tipo de pesquisa volta-se sobremodo a questões emanadas de realidades sociais cujas necessidades ou peculiaridades merecem ser identificadas, analisadas e interpretadas sob a perspectiva científica. Esse tipo de pesquisa envolve a interação social entre o pesquisador ou os pesquisadores e os sujeitos e acontecimentos que, direta ou indiretamente, fornecem as informações necessárias ao estudo. Obtidas de modo sistemático, essas informações dependem da habilidade do investigador e da cooperação dos sujeitos observados. Esse tipo de pesquisa pode envolver um modo de proceder denominado etnográfico, que permite ao pesquisador a entrada no campo a ser observado com liberdade para 
identificar e analisar as relações mais ou menos evidentes no contexto a analisar.

Assim concebida, a metodologia de observação participante permite a concretização de relações comunicativas com pessoas ou grupos da situação investigada e aplica-se tanto à chamada pesquisa participante quanto à pesquisa ação.

Entretanto, a pesquisa-ação, além de ser de natureza participante, supõe interferência na realidade social. É um tipo de pesquisa social e com base empírica, concebida e realizada, segundo Thiollent (1986), em estreita associação com uma ação concreta ou com a resolução de um problema de natureza coletiva. Volta-se, portanto, à solução desse problema ou pelo menos à articulação de forças no sentido de esclarecer e revelar possibilidades ou soluções direcionadas às questões que se apresentam. Assim, interfere positivamente no campo de atuação, ampliando o conhecimento dos pesquisadores sobre a sua realidade $\mathrm{e}$ as condições concretas de solução, podendo inclusive aprofundar o nível de consciência das pessoas ou dos grupos participantes e favorecer o estabelecimento de políticas de ação, ou o levantamento de propostas, visando ao sucesso dessa ação.

Supõe-se que, ao participar deste tipo de investigação, o pesquisador se identifique com a cultura e os valores do grupo ou comunidade, para que transite no campo de pesquisa de modo a desvendar e colaborar na exposição das relações de força em sua complexidade, das contradições, dos espaços de colaboração ou conflito, do exercício de domínio ou coerção, assim como para identificar e construir coincidências de propósitos. Desse modo, se consolidam e esclarecem o objeto e os objetivos da investigação, assim como as concepções teóricas e as possibilidades de construção de novos objetos de conhecimento.

5. Várias denominações têm sido dadas ao conjunto de obras consultadas e comentadas, denominado em alguns casos de Revisão de literatura, em outros de Literatura pertinente e ainda de Referencial teórico. Há diferença entre cada um desses conceitos?

Considero a literatura pertinente como um conjunto de obras cujo conteúdo se relaciona com o tema ou objeto da pesquisa. Segundo esta concepção, seria um produto, algo existente previamente e sobre o qual o pesquisador deverá se debruçar para encontrar apoio teórico. Quanto à revisão da literatura, como processo, expressa um caráter mais exaustivo de busca, visando a levantar o material necessário e pertinente para que se processe a análise e interpretação dos dados que comprovarão hipóteses ou suportarão as ideias defendidas. Dessa busca decorre a seleção e o reconhecimento de um novo conjunto que se costuma denominar como referencial teórico da pesquisa, composto de obras que suportam teoricamente as "teses", com autores, posições e pressupostos que as fundamentam e aos quais se recorre quando da análise e interpretação dos dados. Acredito que o que os diferencia é o comprometimento do pesquisador com as ideias do referencial teórico e a explicitação desse compromisso na construção de seu discurso científico.

\section{As fontes utilizadas na pesquisa podem representar determinantes de sua confiabilidade na comunidade acadêmica. Como identificar fontes seguras e de qualidade para uso como referencial?}

O termo fonte tem forte conotação semântica, sempre como resposta a necessidades vitais por ela atendidas. No caso específico do pesquisador, as fontes responderiam às necessidades da pesquisa. Primárias, secundárias ou terciárias, impressas ou eletrônicas, elas surgem no mundo acadêmico em ritmo acelerado e com dificuldade o pesquisador de uma área conhece todas das quais dispõe, especialmente as fontes primárias, tais como os livros, artigos de periódicos e comunicações em congressos. A constatação de que os benefícios tecnológicos repercutem 
quantitativa e qualitativamente nas fontes de pesquisa se, por um lado, resulta numa euforia tal como a de Midas, diante de seu poder gerador de ouro, tem como contraponto a necessidade de selecionar criteriosamente os elementos relevantes para as respostas às questões levantadas na pesquisa. Para organizar essa documentação variadíssima, destacam-se os Catálogos Públicos de Acesso em Linha (Online Public Access Catalogues - OPAC's) e os catálogos coletivos (Collective Online Public Access Catalogues COPAC's). Com as facilidades oferecidas pelos ambientes de interação por computadores, como videoconferências e plataformas de convergência digital, os diretórios de endereços URL e os repositórios e bibliotecas virtuais e digitais aproximam-se dos objetivos da pesquisa e são mais bem aproveitados graças à convergência e à simultaneidade de alcance das mídias.

Entretanto, as fontes de informação disponíveis, sejam primárias, secundárias ou terciárias, sejam registros convencionais ou eletrônicos, sempre deverão ser autorizadas, confiáveis, seguras e valorizadas pela sua qualidade. Em qualquer domínio científico, por exemplo, temos importantes fontes primárias, pertinentes ao produto deinformação elaborado pelo autor, como artigos, livros, relatórios científicos, patentes, dissertações e teses, cujos registros e textos completos se encontram em fontes denominadas secundárias. Chamadas secundárias por referenciarem as primárias, estas podem ser repositórios, bases de dados ou abstracts, bibliografias, dicionários e enciclopédias, publicações ou periódicos de indexação e resumos, artigos de revisão, catálogos, entre outras fontes que remetem às primárias. As fontes terciárias, por seu turno, são as que remetem às fontes secundárias, tais como as bibliografias de bibliografias, os catálogos de catálogos de bibliotecas e diretórios, entre outros instrumentos impressos ou eletrônicos. Categorizá-las já é difícil, mas atribuir-lhes valores qualitativos é tarefa ainda mais complexa, pois exige critérios relativos à problemática da pesquisa, ao objeto, objetivos e métodos. Para isso, o pensamento crítico deve aliar-se à capacidade de análise das fontes ou veículos de disseminação da informação, tanto em relação ao conteúdo por eles disponível, quanto a sua atualização, ao seu prestígio acadêmico e a sua capacidade comunicativa. A obra sobre fontes de informação em ciência e tecnologia de Cunha (2001) facilita esta resposta, pois amplia o conhecimento de professores, pesquisadores, estudantes, e profissionais da informação sobre os diversos tipos de obras de referência, seja no formato impresso, seja em outro suporte. Quanto às propostas de categorias de avaliação, elas têm sido desenvolvidas especialmente por instituições ao formalizarem seu perfil de compras, especialmente voltado às fontes não convencionais, cada vez mais presentes para acompanhar o ritmo dos avanços tecnológicos. Mas considerando o ponto de vista do pesquisador, cuja escolha é decisiva, não somente para que encontre o que necessita, mas também para que seu trabalho seja valorizado em relação à qualidade de seus referenciais teóricos, pode-se afirmar, a título de síntese, que os mais reiterados critérios e princípios resumemse a categorias como autoridade, pertinência, acuidade, objetividade, atualização e cobertura ou abrangência.

\section{Referências}

BRUYNE, P.; HERMAN, J.; SHOUTHEETE, M. de. Dinâmica da pesquisa em ciências sociais: os pólos da prática metodológica. Rio de Janeiro: Francisco Alves, 1977.

CUNHA, M. B. da. Para saber mais: fontes de informação em ciência e tecnologia. Brasília: Briquet de Lemos/Livros, 2001.

MACHADO-DA-SILVA, C. L.; CUNHA, V. C.; AMBONI, N. Organizações: o estado da arte da produção acadêmica no Brasil. In: ENCONTRO ANUAL DA ANPAD, 14., 1990, Florianópolis. Anais... Florianópolis: ANPAD, 1990.

SILVA, V. da. Perfil metodológico da pesquisa em Ciência da Informação. 2010. Trabalho de Conclusão de Curso (Graduação em Gestão da Informação) - Universidade Federal do Paraná. 


\section{THIOLLENT, M. Metodologia da pesquisa-} ação. São Paulo: Cortez, 1986

VERGARA, S. C.; PECI, A. Escolhas metodológicas em estudos organizacionais. Organizações \& Sociedade, v. 10, n. 27, p. 13- 26, 2003.

\section{Questions about Research Methodology - part 2}

\section{Abstract}

Profa.Dr.Leilah Bufrem Santiago, expertinscientific production and methodology, answers questions from Postgraduate students in Science, Management and Information Technology (PPCGI / UFPR) and Undergraduate Information Management (CGI / UFPR). In this second part of the interview, Profa. Leilah clarifies, emphasizing the peculiarities of research in Applied Social Sciences and Science and Information Management, aspects of: data collection and analysis, differences between action research and participatory research, ways to identify secure and quality sources of references and the characteristics of scientific production.

\section{Keywords}

Scientific method; Social Sciences; Information Science; Scientific research.

Questões elaboradas pelos alunos do Programa de PósGraduação (Mestrado) em Ciência, Gestão e Tecnologia da Informação (PPCGI/SA/UFPR) e alunos do Curso de Graduação em Gestão da Informação (CGI/UFPR).
Leilah é Professora Titular Aposentada do Curso de Gestão da Informação e do Programa de Pós-Graduação em Educação e do Mestrado em Ciência, Gestão e Tecnologia da Informação da Universidade Federal do

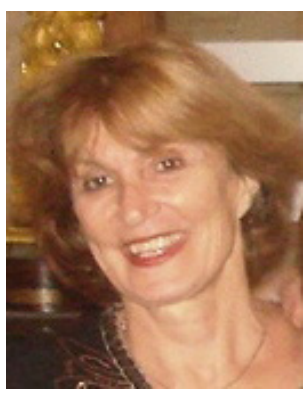
Paraná. Membro de Conselhos Assessores de periódicos científicos. Coordenadora do Grupo de Pesquisa Educação, Pesquisa e Perfil profissional em Informação, pesquisadora do Grupo de Pesquisa Cultura, práticas escolares e educação histórica e do Núcleo de Produção Científica (NPC) da Escola de Comunicações e Artes/USP. Membro do Conselho Fiscal da International Society for Knowledge Organization (ISKO-Brasil). Tem experiência na área de Ciência da Informação e Educação, com ênfase em Metodologia e Produção Científica. Graduada e licenciada em Filosofia pela Pontifícia Universidade Católica do Paraná (1964), graduada em Biblioteconomia e Documentação pela Universidade Federal do Paraná (1963). Mestre em Educação pela Universidade Federal do Paraná (1981), doutora em Ciências da Comunicação pela Universidade de São Paulo (1991), pós-doutora pela Universidad Autónoma de Madrid (1995) e quatro especializações (Ação Cultural - 1987; Cultura Portuguesa - 1975; Métodos e Técnicas de Ensino - 1975; Teoria do Conhecimento - 1974). Tem livros e artigos publicados e orienta teses e dissertações de mestrado e doutorado. Atualmente desempenha atividades docentes e de pesquisa como Professora Visitante Senior da Universidade Federal de Pernambuco e também junto a Universidade Estadual Paulista "Júlio de Mesquita Filho" (UNESP/ Marilia). 